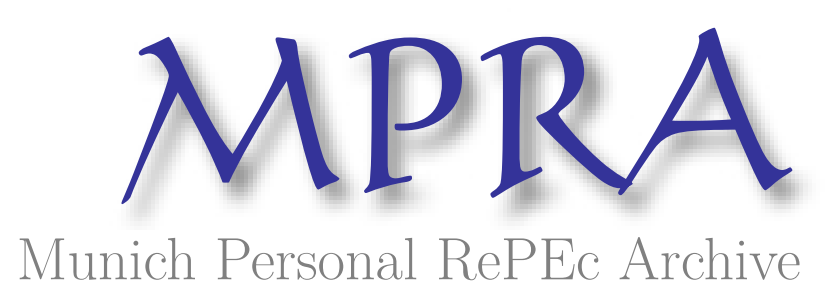

\title{
Forecasting Feds Fund Rate: 1982-2014
}

Mohajeryami, Saeed

university of North Carolina at Charlotte

1 May 2015

Online at https://mpra.ub.uni-muenchen.de/67142/

MPRA Paper No. 67142, posted 09 Oct 2015 15:00 UTC 


\title{
Forecasting Feds Fund Rate: 1982-2014
}

\author{
Saeed Mohajeryami \\ University of North Carolina at Charlotte \\ Belk College of Business \\ Charlotte, NC, USA \\ smohajer@uncc.edu
}

\begin{abstract}
Federal funds rate in the US is the interest rate that the banks pay each other for lending funds overnight. Fed funds rate is an important benchmark in the economy because of its significant impact on many other financial indices. The target rate is determined by Federal Open Market Committee (FOMC). Federal Reserve's method of determining "reaction function" is subject to speculation for a long time. Taylor believed that the reaction function can be specified as a weighted average of deviations of inflation and unemployment from target values. But this model, even though worked for a long time, are under attack by new economists and like many old models are obsolete because of the various structural change in the society and economy. In this work, different models and different parameters are used to determine the reaction function. According to the results, VAR model gives the best FERMS (5.7\%). Another interesting observation is that the inflation rate does not granger-cause Feds fund target rate which is not consistent with Taylor rule. On the other hand, the unemployment rate plays an important role in the Feds reaction function.
\end{abstract}

\section{Introduction}

Federal funds rate in the US is the interest rate that the banks pay each other for lending funds overnight. Institutions with surplus balance in their accounts in Federal Reserve lend funds to the 
banks in need. Fed funds rate is an important benchmark in the economy, because it determines many other financial indices. The target rate is determined by a meeting of the members of federal open market committee (FOMC) eight times a year (almost seven weeks apart).

The way Feds determine the rate is called Federal Reserve's "reaction function". It has been subject to speculation for a long time. Economists are interested to model this function due to its important. This function plays an important role in a wide variety of analyses.

The Federal Reserve operates under a legal mandate to target the price stability and in order to do this job, they monitor different indicators in the economy to make a better decision. What are the variables Feds use in determining the Feds fund are still the subject of debate. Taylor believed that the reaction function can be specified as a weighted average of deviations of inflation and unemployment from target values. But this model, even though worked for a long time, are under attack by new economists and like many old models are obsolete because of the various structural change in the society and economy.

\section{Literature review}

Khoury [1] surveys 42 empirical fed reaction functions from various studies. Ben Bernanke et al. [2] used vector autoregression (VAR) to explain the Fed reaction function. Judd et al. [3] examined the Fed reaction function during the different Fed chairmans. Their main hypothesis is that the model should control for the specific characteristics of each chairman. According to what they found, during Alan Greenspan's tenure, taylor rule type reaction function worked very well. But after him, the effect of the inflation dropped gradually and the effect of the output gap is risen.

Hamilton et al. [4] introduces a new class of models termed autoregressive conditional hazard processes, which allow one to produce dynamic forecasts of the probability of a target change. 
Conditional on a target change, an ordered probit model can produce a forecast. Michael Belongia et al. [5] discuss the evolution of the feds role over the past twenty years. The federal funds rate has evolved from being an intermediate target or indicator variable in discussions of monetary policy to the Federal Reserve's (exogenous) policy instrument. This change has its own implication in the modeling of the reaction function which described in detail. James K. Galbraith et al. [6] explain why they believe the Feds real reaction function is different from what Fed officially claims. According to them, the Feds don't use the inflation in its decision making process and on the other hand, it uses unemployment rate extensively.

After the great recession, FOMC adopted a forward guidance policy which lets the market to know what the expectation of the Fed are. Femia et al. [7] discussed how forward guidance about federal funds rate affect the market players. The paper discussed about how market players come to this conclusion that they should wait till the unemployment dropped to the certain level to expect the Fed to raise the federal funds rate.

\section{Data}

Almost all the data used in this study comes from the database on Federal Reserve Bank of St. Louis called Federal Reserve economics data (FRED). One of the advantages of this database is the capability of determining the timing of the samples. For examples, in this study, the quarterly data is used.

- Federal funds rate is an interest rate at which a depository institution lends funds to another depository institution overnight. This interest rate is important because it affects all other forms of the interest rates and it affect the monetary and financial conditions. The Federal Open 
Market Committee (FOMC), which is the Federal Reserve's primary monetary policymaking body, decides this rate and reports it to the market.

- Personal consumption expenditure (PCE) is a measure of price changes in consumer goods and services. PCE consists of the actual and imputed expenditures of households; the measure includes data pertaining to durables, non-durables and services. In many ways, it's close to consumer price index (CPI), but there are some major differences. CPI is fixed basket of goods while PCE is a broader measure and it reflects the change in the price of more items. PCE is Feds favorite measure of the inflation.

- Output gap is an economic measure of the difference between the actual output of an economy and the output it could achieve when it is most efficient, or at full capacity. A positive output gap occurs when actual output is more than the full-capacity output. Negative output gap occurs when actual output is less than full-capacity output.

- Standard and Poor's 500 index (S\&P500) is an index for 500 stocks selected for size, liquidity and industry sector. Most people agree that the S\&P 500 is a good representation of the U.S. market because of the good size of companies that are included in it. In fact, many consider it to be the definition of the market. There are many other indexes reflecting the different parts of the market, but overall, they have a big correlation which means adding more than one can bring the multicollinearity into the model.

- Consumer confidence index are reported from the multiple sources, two of the main sources are conference board and the University of Michigan. Even though it's called an index, it is actually a monthly poll of household. In Conference board CCI, The participants are asked to respond to five questions, which have remained consistent over the life of the survey. The questions ask the respondents to give their appraisal or expectations about the following: a) 
current business conditions b) business conditions six months hence c) the current employment conditions d) employment conditions in the next six months e) their own total family income in the next six months. There are only three possible answers the participants can give to these questions: positive, negative or neutral. For CBCCI, the benchmark is 1985 which is assigned a CCI value of 100 .

- Unemployment rate is the percentage of the total labor force that is unemployed but actively seeking employment and willing to work.

\section{Unit root test}

\section{A. Federal Funds Target Rate (FFTR)}

For testing the unit root test, the DF-GLS is used. The DF-GLS test results for the FFTR (level form) is shown in fig. 1. For the DF-GLS test, the null hypothesis (H0), is being the non-stationary and the alternative hypothesis (H1) is stationary. FFTR in theory doesn't have any trend. It can be categorized as single mean. According to the results, we fail to reject the null hypothesis. The critical value for intercept only of DF-GLS is -1.95 and the DF-GLS value is -0.0658 . it means the data is non-stationary. This result can be verified by looking at the autocorrelation function (ACF) and partial autocorrelation function (PACF).

\begin{tabular}{|l|r|r|r|r|r|r|}
\hline \multicolumn{7}{|c|}{ ERS Unit Root Test } \\
\hline Type & Lags & Variance & PT & Pr $<$ PT & DF-GLS & Pr < DFGLS \\
\hline Single Mean & 8 & 0.5604 & 22.2446 & 0.6394 & -0.0658 & $<.0001$ \\
\hline Trend & 8 & 0.5604 & 5.8027 & 1.0000 & -4.0667 & 0.0019 \\
\hline
\end{tabular}

Figure 1: DF-GLS test for FFTR

For solving the problem of non-stationary data, the first difference of FFTR (dFFTR) is used and the unit root test is done on that. The DF-GLS test results for the dFFTR is shown in fig. 2. 
According to the results, we can reject the null hypothesis. The critical value for intercept only of DF-GLS is -1.95 and the DF-GLS value is -2.07 . It means the data is stationary. This result can be verified by looking at the autocorrelation function (ACF) and partial autocorrelation function (PACF).

\begin{tabular}{|l|r|r|r|r|r|r|}
\hline \multicolumn{7}{|c|}{ ERS Unit Root Test } \\
\hline Type & Lags & Variance & PT & Pr $<$ PT & DF-GLS & Pr $<$ DFGLS \\
\hline Single Mean & 7 & 42.4860 & 0.0050 & $<.0001$ & -2.0749 & $<.0001$ \\
\hline Trend & 7 & 42.4860 & 0.0104 & 0.7864 & -3.3182 & 0.0207 \\
\hline
\end{tabular}

Figure 2: DF-GLS test for dFFTR

\section{B. Output Gap (OG)}

The DF-GLS test results for the OG is shown in fig. 3. According to the results, we fail to reject the null hypothesis. The critical value for intercept only of DF-GLS is -1.95 and the DF-GLS value is -1.036 . It means the data is non-stationary. The first difference of $\mathrm{OG}(\mathrm{dOG})$ is tested again. The results are shown in fig. 4. Based off of the results, we can reject the null hypothesis. The DFGLS value is -3.13 . It means the data is stationary.

\begin{tabular}{|l|r|r|r|r|r|r|}
\hline \multicolumn{7}{|c|}{ ERS Unit Root Test } \\
\hline Type & Lags & Variance & PT & Pr $<$ PT & DF-GLS & Pr $<$ DFGLS \\
\hline Single Mean & 3 & 0.0001 & 10.6582 & 0.3759 & -1.0369 & $<.0001$ \\
\hline Trend & 3 & 0.0001 & 16.6334 & 1.0000 & -1.7213 & 0.5325 \\
\hline
\end{tabular}

Figure 3: DF-GLS test of OG 


\begin{tabular}{|l|r|r|r|r|r|r|}
\hline \multicolumn{7}{|c|}{ ERS Unit Root Test } \\
\hline Type & Lags & Variance & PT & Pr $<$ PT & DF-GLS & Pr $<$ DFGLS \\
\hline Single Mean & 3 & 0.0000 & 1.1033 & 0.0005 & -3.1389 & $<.0001$ \\
\hline Trend & 3 & 0.0000 & 2.9980 & 0.9999 & -3.9745 & 0.0027 \\
\hline
\end{tabular}

Figure 4: DF-GLS test of $d O G$

\section{C. inflation (PCEPDC)}

The DF-GLS test results for the PCEPDC is shown in fig. 5. According to the results, we can reject the null hypothesis. The critical value for intercept only of DF-GLS is -1.95 and the DFGLS value is -2.20 . It means the data is stationary.

\begin{tabular}{|l|r|r|r|r|r|r|}
\hline \multicolumn{7}{|c|}{ ERS Unit Root Test } \\
\hline Type & Lags & Variance & PT & Pr $<$ PT & DF-GLS & Pr $<$ DFGLS \\
\hline Single Mean & 3 & 1.3344 & 2.1932 & 0.0169 & -2.2048 & $<.0001$ \\
\hline Trend & 3 & 1.3344 & 2.2417 & 0.9981 & -4.7023 & 0.0003 \\
\hline
\end{tabular}

Figure 5: DF-GLS test of PCEPDC

\section{S\&P 500 index (SP500C)}

The DF-GLS test results for the SP500C is shown in fig. 6. According to the results, we fail to reject the null hypothesis. The critical value for intercept only of DF-GLS is -1.95 and the DFGLS value is -1.44. It means the data is non-stationary. The first difference of OG (dSP500C) is tested again. The results are shown in fig.7. Based off of the results, we can reject the null hypothesis. The DF-GLS value is -2.675 . It means the data is stationary. 


\begin{tabular}{|l|r|r|r|r|r|r|}
\hline \multicolumn{7}{|c|}{ ERS Unit Root Test } \\
\hline Type & Lags & Variance & PT & Pr $<$ PT & DF-GLS & Pr $<$ DFGLS \\
\hline Single Mean & 3 & 0.0031 & 2.6903 & 0.0328 & -1.4450 & $<.0001$ \\
\hline Trend & 3 & 0.0031 & 3.4177 & 0.9999 & -2.8115 & 0.0767 \\
\hline
\end{tabular}

Figure 6: DF-GLS test of SP500C

\begin{tabular}{|l|r|r|r|r|r|r|}
\hline \multicolumn{7}{|c|}{ ERS Unit Root Test } \\
\hline Type & Lags & Variance & PT & Pr $<$ PT & DF-GLS & Pr $<$ DFGLS \\
\hline Single Mean & 3 & 0.0275 & 0.1201 & $<.0001$ & -2.6753 & $<.0001$ \\
\hline Trend & 3 & 0.0275 & 0.2969 & 0.8564 & -4.7794 & 0.0002 \\
\hline
\end{tabular}

Figure 7: DF-GLS test of dSP500C

\section{E. Consumer Confidence Sentiment (CCC)}

The DF-GLS test results for the CCC is shown in fig. 8. According to the results, we can reject the null hypothesis. The critical value for intercept only of DF-GLS is -1.95 and the DF-GLS value is -4.39 . It means the data is stationary.

\begin{tabular}{|l|r|r|r|r|r|r|}
\hline \multicolumn{7}{|c|}{ ERS Unit Root Test } \\
\hline Type & Lags & Variance & PT & Pr $<$ PT & DF-GLS & Pr $<$ DFGLS \\
\hline Single Mean & 3 & 0.0063 & 0.9211 & 0.0001 & -4.3911 & $<.0001$ \\
\hline Trend & 3 & 0.0063 & 3.1111 & 0.9999 & -4.9856 & 0.0001 \\
\hline
\end{tabular}

Figure 8: DF-GLS test of CCC

\section{E. Unemployment rate (URC)}

The DF-GLS test results for the URC is shown in fig. 9. According to the results, we fail to reject the null hypothesis. The critical value for intercept only of DF-GLS is -1.95 and the DFGLS value is -1.90 . It means the data is non-stationary. But since the value is marginal and it can be accepted with $10 \%$ significance level. It's used in the study without any change. 


\begin{tabular}{|l|r|r|r|r|r|r|}
\hline \multicolumn{7}{|c|}{ ERS Unit Root Test } \\
\hline Type & Lags & Variance & PT & Pr $<$ PT & DF-GLS & Pr $<$ DFGLS \\
\hline Single Mean & 3 & 0.0690 & 3.9000 & 0.0852 & -1.9033 & $<.0001$ \\
\hline Trend & 3 & 0.0690 & 4.9137 & 1.0000 & -3.3987 & 0.0163 \\
\hline
\end{tabular}

Figure 9: DF-GLS test of URC

\section{Econometric model and results}

\section{A. AR(1) model}

AR (1) model is used as a bench mark, for comparing the results of the forecasting, the data is split to two data set. One is from 1982Q4 to 2012Q4 and the other one is 2013Q1 to 2014Q4 for testing the forecasting.

TABLE 1: FORECASTING RESULTS OF AR(1) MODEL

\begin{tabular}{|c|c|c|c|}
\hline Period & Forecast & Actual value & difference \\
\hline 2013Q1 & -0.043494044 & 0 & 0.043494044 \\
\hline 2013Q2 & -0.072468958 & 0 & 0.072468958 \\
\hline 2013Q3 & -0.084928051 & 0 & 0.084928051 \\
\hline 2013Q4 & -0.088669087 & 0 & 0.088669087 \\
\hline 2014Q1 & -0.089200953 & 0 & 0.089200953 \\
\hline 2014Q2 & -0.088966649 & 0 & 0.088966649 \\
\hline 2014Q3 & -0.088726876 & 0 & 0.088726876 \\
\hline 2014Q4 & -0.088604009 & 0 & 0.088604009 \\
\hline \multicolumn{4}{|c|}{ FERMS $=0.082$} \\
\hline
\end{tabular}




\section{B. ARIMA model}

The first step is to determine the $\mathrm{p}, \mathrm{d}$ and $\mathrm{q}$ in $\operatorname{ARIMA}(\mathrm{p}, \mathrm{d}, \mathrm{q})$. For that purpose the SCAN option in SAS provides the useful information. The result of the SCAN is provided in fig. 10. For ARIMA model, the values of $\mathrm{p}=1$ and $\mathrm{q}=1$ are used.

\begin{tabular}{|r|r|}
\hline $\begin{array}{c}\text { ARMA(p+d,q) } \\
\text { Tentative } \\
\text { Order Selection } \\
\text { Tests }\end{array}$ \\
\hline SCAN \\
\hline$p+d$ & $\mathbf{q}$ \\
\hline 1 & 1 \\
\hline 0 & 2 \\
\hline 3 & 0 \\
\hline
\end{tabular}

Figure 10: SCAN resutls

TABLE 2: FORECASTING RESULTS FOR ARIMA $(1,0,1)$

\begin{tabular}{|c|c|c|c|}
\hline Period & Forecast & Actual value & difference \\
\hline 2013Q1 & -0.045015368 & 0 & 0.045015368 \\
\hline 2013Q2 & -0.079435203 & 0 & 0.079435203 \\
\hline $2013 \mathrm{Q} 3$ & -0.086250754 & 0 & 0.086250754 \\
\hline 2013Q4 & -0.087600317 & 0 & 0.087600317 \\
\hline 2014Q1 & -0.087867547 & 0 & 0.087867547 \\
\hline 2014Q2 & -0.087920462 & 0 & 0.087920462 \\
\hline 2014Q3 & -0.087930939 & 0 & 0.087930939 \\
\hline 2014Q4 & -0.087933014 & 0 & 0.087933014 \\
\hline & FERI & & \\
\hline
\end{tabular}


C. ADL model

C.1. checking $A D L(1,1), A D L(2,2), A D L(3,3), A D L(4,4)$ for dFFTR and dOG

TABLE 3: ADL ANALYSIS BY SBC FOR DFFTR AND DOG

\begin{tabular}{|c|c|}
\hline \multicolumn{2}{|c|}{ dFFTR (dependent variable) and dOG( explanatory variable) } \\
\hline model & SBC \\
\hline ADL $(1,1)$ & 123.45 \\
\hline $\operatorname{ADL}(2,2)$ & 130.66 \\
\hline $\operatorname{ADL}(3,3)$ & 136.09 \\
\hline $\operatorname{ADL}(4,4)$ & 144.37 \\
\hline
\end{tabular}

C.2. checking ADL(1,1), ADL(2,2), ADL(3,3), ADL(4,4) for dFFTR and dSP500C

TABLE 4: ADL ANALYSIS BY SBC FOR DFFTR AND DSP500C

\begin{tabular}{|c|c|}
\hline \multicolumn{2}{|c|}{ dFFTR (dependent variable) and dSP500C ( explanatory variable) } \\
\hline model & SBC \\
\hline $\operatorname{ADL}(1,1)$ & 136.5 \\
\hline $\operatorname{ADL}(2,2)$ & 143.5 \\
\hline $\operatorname{ADL}(3,3)$ & 144.61 \\
\hline $\operatorname{ADL}(4,4)$ & 152.42 \\
\hline
\end{tabular}


C.3. checking $A D L(1,1), A D L(2,2), A D L(3,3), A D L(4,4)$ for $d F F T R$ and CCC

TABLE 5: ADL ANALYSIS BY SBC FOR DFFTR AND CCC

\begin{tabular}{|c|c|}
\hline \multicolumn{2}{|c|}{ dFFTR (dependent variable) and CCC ( explanatory variable) } \\
\hline model & SBC \\
\hline $\operatorname{ADL}(1,1)$ & 142.22 \\
\hline $\operatorname{ADL}(2,2)$ & 144.87 \\
\hline $\operatorname{ADL}(3,3)$ & 148.86 \\
\hline $\operatorname{ADL}(4,4)$ & 151.13 \\
\hline
\end{tabular}

C.4. checking ADL(1,1), ADL(2,2), ADL(3,3), ADL(4,4) for dFFTR and URC

TABLE 6: ADL ANALYSIS BY SBC FOR DFFTR AND URC

\begin{tabular}{|c|c|}
\hline \multicolumn{2}{|c|}{ dFFTR (dependent variable) and URC ( explanatory variable) } \\
\hline model & SBC \\
\hline ADL $(1,1)$ & 131.5 \\
\hline $\operatorname{ADL}(2,2)$ & 136.7 \\
\hline $\operatorname{ADL}(3,3)$ & 142.18 \\
\hline $\operatorname{ADL}(4,4)$ & 141.34 \\
\hline
\end{tabular}

According to the results of table 3 to 6 , ADL $(1,1)$ of dFFTR (dependent variable) and dOG( explanatory variable) gives the best result. 
C.5. forecasting results for ADL(1,1) model of dFFTR and dOG

\begin{tabular}{|c|c|c|c|}
\hline Period & Forecast & Actual value & difference \\
\hline $2013 \mathrm{Q} 1$ & -0.1581 & 0 & 0.1581 \\
\hline $2013 \mathrm{Q} 2$ & -0.0202 & 0 & 0.0202 \\
\hline $2013 \mathrm{Q} 3$ & -0.0427 & 0 & 0.0427 \\
\hline $2013 \mathrm{Q} 4$ & 0.0710 & 0 & 0.0710 \\
\hline $2014 \mathrm{Q} 1$ & 0.0807 & 0 & 0.0807 \\
\hline $2014 \mathrm{Q} 2$ & -0.2649 & 0 & 0.2649 \\
\hline $2014 \mathrm{Q} 3$ & 0.0730 & 0 & 0.0730 \\
\hline $2014 \mathrm{Q} 4$ & 0.1637 & 0 & 0.1637 \\
\hline & \multicolumn{2}{|c|}{ FERMS $=0.132$} & \\
\hline
\end{tabular}

\section{VAR model}

\section{D.1. Granger causality test for five variables}

The null hypothesis of the Granger causality test is that group 1 is influenced only by itself, and not by group 2 . Except test 3, in the other test, the null hypothesis can be rejected. It means they are interdependent. Test 3 suggest that inflation doesn't belong to the model. Therefore, in the model used for the forecasting, the inflation is dropped. 


\begin{tabular}{|l|r|r|r|}
\hline \multicolumn{3}{|c|}{ Granger-Causality Wald Test } \\
\hline Test & DF & Chi-Square & Pr $>$ ChiSq \\
\hline 1 & 5 & 20.96 & 0.0008 \\
\hline 2 & 5 & 13.35 & 0.0203 \\
\hline 3 & 5 & 8.94 & 0.1115 \\
\hline 4 & 5 & 20.24 & 0.0011 \\
\hline 5 & 5 & 47.07 & $<.0001$ \\
\hline 6 & 5 & 20.16 & 0.0012 \\
\hline Test 1: Group 1 Variables: & dFFTR \\
\hline Group 2 Variables: & dOG PCEPDC dSP500C CCC URC \\
\hline Test 2: Group 1 Variables: & dOG \\
\hline Group 2 Variables: & dFFTR PCEPDC dSP500C CCC URC \\
\hline Test 6: Group 1 Variables: & URC \\
\hline Group 2 Variables: & dFFTR dOG PCEPDC dSP500C CCC \\
\hline Test 3: Group 1 Variables: & PCEPDC \\
\hline Group 2 Variables: & dFFTR dOG dSP500C CCC URC \\
\hline Test 4: Group 1 Variables: & dSP500C \\
\hline Group 2 Variables: & dFFTR dOG PCEPDC CCC URC \\
\hline
\end{tabular}

Figure 11: Granger causality test

\section{D.2. determining the number of variables}

According to the results of table 7. Output gap, S\&P500 index, consumer confidence sentiment and unemployment rate belong to the model.

TABLE 7: DETERMINING THE VARIABLES THAT BELONGS TO THE MODEL BY SBC INFORMATION CRITERION

\begin{tabular}{|c|c|c|}
\hline Combination & SBC & Comment \\
\hline dFFTR dOG & $\mathbf{- 1 2 . 1 9}$ & Output gap (OG) belongs to the model \\
\hline dFFTR dOG PCEPDC & $\mathbf{- 1 1 . 4 7}$ & $\begin{array}{c}\text { Inflation (PCEPDC) doesn't seem to be relevant } \\
\text { anymore }\end{array}$ \\
\hline dFFTR dOG SP500C & $\mathbf{- 1 7 . 4 0}$ & SP500 belongs to the model \\
\hline dFFTR dOG dSP500C CCC & $\mathbf{- 2 2 . 0 8}$ & Consumer confidence (CCC) belongs to the model \\
\hline $\begin{array}{c}\text { dFFTR dOG dSP500C CCC } \\
\text { URC }\end{array}$ & $\mathbf{- 2 5 . 4 4}$ & $\begin{array}{c}\text { Unemployment rate (URC) belongs to the model } \\
\end{array}$ \\
\hline
\end{tabular}




\section{D.3. determining the proper lag order of the model}

It's found that Output gap, S\&P500 index, consumer confidence sentiment and unemployment rate can be a good explanatory variables, the next step is to determine which lag order is appropriate for the forecast. SBC is used for the evaluation purpose. The lag order 1 gives the best results.

\begin{tabular}{|c|c|}
\hline \multicolumn{2}{|c|}{ dFFTR dOG dSP500C CCC URC VAR model } \\
\hline Lag Order & SBC \\
\hline 1 & -25.44 \\
\hline 2 & -25.10 \\
\hline 3 & -24.49 \\
\hline
\end{tabular}

\section{D.4. forecasting results}

\begin{tabular}{|c|c|c|c|}
\hline Period & Forecast & Actual value & difference \\
\hline $2013 \mathrm{Q} 1$ & -0.04038595 & 0 & 0.04038595 \\
\hline $2013 \mathrm{Q} 2$ & -0.065526826 & 0 & 0.065526826 \\
\hline $2013 \mathrm{Q} 3$ & -0.047697675 & 0 & 0.047697675 \\
\hline $2013 \mathrm{Q} 4$ & -0.053842146 & 0 & 0.053842146 \\
\hline $2014 \mathrm{Q} 1$ & -0.058761933 & 0 & 0.058761933 \\
\hline $2014 \mathrm{Q} 2$ & -0.061094191 & 0 & 0.061094191 \\
\hline $2014 \mathrm{Q} 3$ & -0.063778347 & 0 & 0.063778347 \\
\hline $2014 \mathrm{Q} 4$ & -0.06562991 & 0 & 0.06562991 \\
\hline & \multicolumn{2}{|c|}{ FERMS $=0.05772701095$} & \\
\hline
\end{tabular}




\section{Forecasting for the next 2 years (eight quarters)}

According to the results of this study, VAR model gives the best results, so, the Feds fund target rate is forecasted for the next 2 years with this model.

\begin{tabular}{|c|c|}
\hline Period & Forecast \\
\hline $2015 \mathrm{Q} 1$ & 0.05690 \\
\hline $2015 \mathrm{Q} 2$ & 0.06883 \\
\hline $2015 \mathrm{Q} 3$ & 0.05087 \\
\hline $2015 \mathrm{Q} 4$ & 0.02581 \\
\hline $2016 \mathrm{Q} 1$ & 0.00381 \\
\hline $2016 \mathrm{Q} 2$ & -0.01389 \\
\hline $2016 \mathrm{Q} 3$ & -0.02722 \\
\hline $2016 \mathrm{Q} 4$ & -0.03692 \\
\hline
\end{tabular}

\section{Conclusion}

According to the results, VAR model gives the best FERMS (5.7\%). One of the problemd in this study is that the forecasted results are negative while Feds fund target rate cannot be negative. This is a censored data problem. Techniques like Heckman test can be used to solve the censored data problem. But it's beyond the scope of this project and it can be applied to the model to improve the accuracy.

Another interesting observation is that the inflation rate doesn't granger cause Feds fund target rate which is not consistent with Taylor rule. It can be interpreted this way that the inflation is not 
the concern of Feds anymore and they don't factor in the inflation rate into their calculations. On the other hand, the unemployment rate plays an important role in the Feds reaction function.

\section{References}

[1] Khoury, Salwa S. 1990. “The /federal Reserve Reaction Function: A Specification Search.” In the Political Economy of American Monetary Policy, ed. Thomas Mayer. Cambridge, England: Cambridge University Press, pp. 27-41.

[2] Bernanke, Ben S., and Alan S. Blinder. 1992." The Federal Funds Rate and the Channels of Monetary Transmission.” American Economic Review 82, pp. 901-921

[3] Judd, John P., and Glenn D. Rudebusch. "Taylor's Rule and the Fed: 1970-1997." Economic Review-Federal Reserve Bank of San Francisco (1998): 3-16.

[4] Hamilton, James D., and Oscar Jorda. “A model for the federal funds rate target”. No. w7847. National bureau of economic research, 2000.

[5] Belongia, Michael, and Melvin Hinich. "The evolving role and definition of the federal funds rate in the conduct of US monetary policy." (2009).

[6] Galbraith, James K., Olivier G. Giovannoni, and Ann J. Russo. "The Fed's Real Reaction Function Monetary Policy, Inflation, Unemployment, Inequality-and Presidential Politics." (2007).

[7] Femia, Katherine, Steven Friedman, and Brian P. Sack. "The Effects of Policy Guidance on Perceptions of the Fed's Reaction Function." FRB of New York Staff Report 652 (2013). 